deficiencies and insufficient/unsafe levels of staffing. The associated declining self-respect, frustration, and guilt cause work-dissatisfaction, burnout, turnover, and consequently, diminished patient care. In this survey study, perceived appropriateness of care and levels of moral distress were evaluated across time. We also determined if respondents' background predicted moral distress levels.

Methods After baseline assessment (background, moral distress, ethical climate), nurses and physicians of our level-III NICU evaluated day-levels of perceived appropriateness of care, the different aspects of moral distress, and ethical climate, at the end of five randomly selected shifts.

Results Response rate: nurses 87(77\%)/physicians 30(91\%). Moral distress (range 1-16) was low at baseline $(\mathrm{M}=2.21$; SD $=1.55)$, but significantly higher for nurses than for physicians $(\mathrm{M}=2.40 / \mathrm{SD}=1.68$ vs $\mathrm{M}=1.68 / \mathrm{SD}=0.98 ; \mathrm{p}=0.01)$. Nurses were less likely to disagree with treatment than physicians $(\mathrm{OR}=2.62, \mathrm{p}=0.02)$. Moral distress at day-level (range1-4) was very low $(\mathrm{M}=0.08 / \mathrm{SD}=0.21)$ and significantly depended on being religious $(\beta=0.16 ; 95 \% \mathrm{CI}=0.03$ to $0.28)$ and perceived 'overtreatment' $(\beta=0.18 ; 95 \% \mathrm{CI}=0.07$ to 0.30$)$, contrary to 'undertreatment' $(\beta=0.17 ; 95 \% \mathrm{CI}-0.63$ to 0.29 ). Highest scores were observed for the following aspects of moral distress: provider (dis)continuity, communication about patient care, and (un)safe levels of staffing.

Conclusion In earlier studies, 'expressing concerns' and 'facilitated ethics conversations' proved to diminish moral distress. Possibly in our NICU the existence of structured-multi-disciplinary-medical-ethical-decision-making explains the (very)low levels of moral distress.

\section{PO-0973 LIFESTYLES, EATING AND ACTIVITY FOR FAMILIES (LEAF) PROGRAMME: DEVELOPING A TIER 3 INTERVENTION FOR WEIGHT MANAGEMENT IN THE EARLY YEARS}

N Sauven, R Brandreth, KE Laity, H Vickerstaff. Paediatrics, Royal Cornwall Hospital Trust, Truro, UK

\subsection{6/archdischild-2014-307384.1591}

Aim To develop a Tier 3, family-focused weight management intervention for the early years.

Background In the UK roughly 1 in 4 children are overweight or obese by the time they start primary school. According to the literature there are no proven models for working with children under 6 years with extreme obesity. We were required to develop a Tier 3 weight management intervention as part of the Care Pathway for Children's Weight Management in Cornwall.

Methodology A review of national guidance and both nationally and locally run programmes for children's weight management was undertaken. The key aspects for successful interventions, appropriate for the early years, were identified. A pilot programme was then developed by our team.

Results Successful programmes were already running for children aged 7-13 years The LEAF (Lifestyles, Eating and Activity for Families) clinic was developed for children 6 years and under. It comprises a multi-disciplinary clinic with Community Paediatrician, Specialist Children Dietician and Specialist Activity Advisor, followed by a group intervention in a community setting, before multi-disciplinary follow-up. The intervention covers a broad range of topics that aim to help empower parents to make changes that ultimately improve the body mass index of their children. After completion of the programme families are discharged, with the specialist team providing support to primary care professionals. Co-morbidities identified including raised LFTs, deranged lipids and sleep apnoea have been improved with this intervention.

Conclusion Initial results are promising but full evaluations of the outcomes of our programme are needed.

\section{P0-0974 CARE OF CHILDREN AND YOUNG PEOPLE WITH DELIBERATE SELF-HARM:ARE WE DOING IT RIGHT?}

L Wajid, M Aziz, H Bentur. General Paediatrics, Whiston Hospital, Liverpool, UK

\subsection{6/archdischild-2014-307384.1592}

Background and aim Deliberate Self-harm (DSH) affects 1 in 15 young people and remains one of top 5 causes of acute hospital admissions in UK. We looked at children attending hospital with DSH to assess their pathways of care and discharge outcomes. We also looked to see if any trends emerged in their attendance to hospital.

Methods Retrospective review of patients over 6 month's period from March to August 2012.

Results 135-patients were identified, 124 with diagnosis of selfharm and 11 with previous mental health problems. Following their attendance to emergency department 90\% (n122) needed inpatient assessment and $96 \%$ of these were followed-up by mental health team. Average length of stay was $3 \mathrm{~h}$ to 6 days. Thoughts of harm included $81 \%$ (n100), drug overdose $50 \%$ (n62) and physical injury 37\% (n46). Analgesics were most common drug overdose in 26\% (n29) and medical interventions was needed in 19\% (n12). 61\% (n83) were girls. Social factors like parental-separation was seen in 61\% (n82), living in supported accommodation in $26 \%$ (n35), family history of mental illness in $23 \%$ (n31) and social-services involved in 38\% (n52).

Conclusion We found that most of our patients had significant DSH needing inpatient management (5\% of our admissions) and majority needed follow-up with mental health services which reinforces the need to work closely with mental health team. Social risk factors were commonly found in our cohort. Recognition and early intervention may reduce the incidence of selfharm in these children. Analgesics were the most common drug of overdose reflecting the easy availability of these to children.

\section{PO-0975 KNOWLEDGE, ATTITUDE AND BARRIERS TOWARDS RESEARCH IN THE NATIONAL HEALTH SERVICE (NHS)}

${ }^{1}$ M Ahmed, ${ }^{2} \mathrm{~S}$ Boswell, ${ }^{2} \mathrm{C}$ Lawrie. ${ }^{1}$ Paediatrics, Burton Hospitals NHS Foundation Trust, Burton on Trent, UK; ${ }^{2}$ Research and Development, Burton Hospitals NHS Foundation Trust, Burton on Trent, UK

\subsection{6/archdischild-2014-307384.1593}

Background In the 21st century, healthcare professionals know a great deal about health, disease and medicine. However, much remains uncertain and continued investment in research aims to find better ways of managing patients, improving public health, reducing health inequalities and keeping people in a state of good health. Clinical Research Networks are well established across the NHS to ensure that all patients and clinicians are able to share the benefits of participating in clinical research. Barriers to research can deter healthcare professionals from contributing towards useful research projects. 